\section{Hyperuricemia and associated factors: a cross- sectional study of Japanese-Brazilians}

\author{
Hiperuricemia e fatores associados: um estudo \\ transversal com nipo-brasileiros
}

\author{
1 Universidade Federal de São \\ Paulo, São Paulo, Brasil. \\ 2 Departamento de Medicina \\ Preventiva, Universidade \\ Federal de São Paulo, São \\ Paulo, Brasil. \\ 3 Faculdade de Saúde \\ Pública, Universidade de São \\ Paulo, São Paulo, Brasil. \\ Correspondence \\ J. Poletto \\ Universidade Federal de \\ São Paulo. \\ Rua Osiris de Camargo 100, \\ apto. 21, bloco 5, São Paulo, SP \\ 05782-440, Brasil. \\ jupoletto@gmail.com
}

\begin{abstract}
This cross-sectional study aimed to estimate the prevalence of hyperuricemia and associated risk factors among Japanese-Brazilians. We obtained data on demographic, health history, food intake, and laboratory variables. Chi-square and prevalence ratios were used as measures of association. $35.3 \%$ of the subjects presented hyperuricemia, which was more frequent in smokers, males, age $\geq$ 55 years, with co-morbidities, individuals on uric acid-increasing medication, serum creatinine $>$ $1.4 m g / d L$, high alcohol consumption, and low consumption of milk and dairy products. In the multivariate analysis, the associations remained significant with gender, overweight, central obesity, hypertriglyceridemia, and use of specific drugs. Among males, low intake of saturated fat was associated with hyperuricemia. Individuals with hypertension showed a negative association with dairy product consumption. The high hyperuricemia prevalence suggests that changes in nutritional profile and control of associated co-morbidities could help minimize occurrence of this condition.
\end{abstract}

Hyperuricemia; Diet; Japanese-Brazilians

\author{
Juliana Poletto 1 \\ Helena Aiko Harima 2 \\ Sandra Roberta Gouvea Ferreira 3 \\ Suely Godoy Agostinho Gimeno 2
}

\section{Introduction}

The scientific literature makes widespread reference to the association between chronic noncommunicable diseases, especially rheumatic and cardiovascular diseases, and hyperuricemia 1,2,3. The relationship between excess plasma uric acid and gout is described in the literature, but despite all the studies and technological advances, there is still limited evidence to show a direct relationship between hyperuricemia and cardiovascular diseases $3,4,5$.

According to previous studies, some foods can help increase or decrease the serum uric acid levels $6,7,8$, depending on their purine content. There is still little information on the exact amount of purines contained in foods, since their content and availability depend on the food processing procedures, among other factors 4,9,10.

Various studies $3,8,11,12,13$ have pointed to excessive intake of fat, alcohol, and fructose, as well as changes in body weight (both excess weight and sudden weight loss) as risk factors for hyperuricemia. In addition, a reduction in the consumption of protein-rich foods (especially animal protein) can help decrease the blood uric acid levels 11,13. The literature includes reports that excess body fat may be the most important nutritional factor for hyperuricemia 2,4,14.

According to previous publications, hyperuricemia is associated with various chronic diseases such as arterial hypertension, cardio- 
vascular diseases, obesity, dyslipidemias, diabetes mellitus, metabolic syndrome, gout, and some neoplasms which increase the risk of death themselves 5,15,16,17. Gout is a rheumatic disease characterized by the deposit of sodium monourate in the joints and periarticular tissues, and is one of the main diseases resulting from hyperuricemia. Individuals with gout have low quality of life resulting from activity-limiting symptoms like intense pain and inflammation of the affected joints $1,2,13$.

Importantly, some medicines indicated for the treatment of the above-mentioned chronic diseases (like arterial hypertensions and neoplasms) include elevated plasma uric acid levels as one of their side effects $2,4,5,14,18$.

Studies among first-generation (Issei) and second-generation (Nisei) Japanese immigrants residing in Bauru, São Paulo State, Brazil, show that these individuals present high prevalence rates for these chronic diseases: excess weight (22.4\%), central obesity (67\%), arterial hypertension $(42.4 \%$ in Isseis and $33.2 \%$ in Niseis), dyslipidemia (81.9\% in Isseis and $77.4 \%$ in Niseis) 19 , altered fasting glucose (18\%), decreased glucose tolerance $(32 \%)$, diabetes mellitus $(29 \%)$, and metabolic syndrome $(47,3 \%) 20$. Given this situation, the current study aimed to estimate the prevalence of hyperuricemia among these individuals and identify metabolic, anthropometric, dietary, and lifestyle risk factors associated with this condition.

\section{Methodology}

This study used data from cross-sectional epidemiological research from the second phase of a study by the Japanese-Brazilian Diabetes Study Group (JBDSG) in the Japanese-Brazilian community (Japanese and their descendents) in the municipality of Bauru, from 1999 to 2000. The research project was approved by the Institutional Review Board of the Federal University in São Paulo (UNIFESP).

In the original research, following a census of the Japanese-Brazilian community in Bauru, the next step was to identify and invite to participate in the study all the first-generation (born in Japan) and second-generation individuals (children of the first generation, born in Brazil, excluding children of ethnic intermarriage), age $\geq 30$ years, totaling 1,751 Japanese-Brazilians of both genders. Of the total group invited to participate, 1,330 accepted (76\%). Of the 421 (24\%) that did not participate, 57 had moved out of the municipality or out of the country, 94 died before or during the data collection period, and 270 refused to participate in the study. Details on the study design have been published elsewhere 20,21.

After agreeing to participate in the study by signing a free and informed consent form, participants were interviewed by trained interviewers using standardized, previously tested questionnaires in order to obtain information on sociodemographic aspects (gender, age, generation, and marital status), health - personal and family history of illnesses (systemic arterial hypertension, dyslipidemia, glucose intolerance, cancer, and regular use of medications), and smoking.

Food consumption was assessed with a food frequency questionnaire, previously validated for Japanese-Brazilians 22. Participants were asked about their habitual food and food-group consumption (122 items) during the previous year. Dietary nutrients were calculated using Dietsys 4.01 (National Cancer Institute, Bethesda, USA) 23. The nutrient databases used were from the United States Department of Agriculture, in addition to the food chemical composition tables for Brazil 24 and Japan 25.

In order to study the relationship between hyperuricemia and dietary variables, we analyzed the data for consumption of alcohol, total calories, carbohydrates, proteins, lipids, and the food groups with the highest content of purines or that in some way impact serum uric acid concentration, like red meats, processed meats, milk and dairy products, and fruits (no food consumption information was available for 47 subjects).

The physical exams and laboratory tests were performed at the Hospital for Rehabilitation of Cranio-Facial Anomalies in Bauru. Body weight was measured in kilograms on a platform-type anthropometric scale (Filizola brand) with a capacity of $200 \mathrm{~kg}$ and accurate to $100 \mathrm{~g}$, positioned on a flat surface and calibrated at each weighing. Individuals were weighed barefoot and wearing as little clothing as possible. Height was measured with a manual stadiometer, attached to the wall, with a capacity of 2 meters and accurate to $1 \mathrm{~cm}$, with the individual barefoot and the buttocks, trunk, and head pressed against the wall, without a baseboard, and on a smooth flat surface and with arms hanging by the individual's side. Body mass index (BMI) was calculated as weight (in kilograms), divided by height (in meters) squared. We adopted the recommendations of the World Health Organization (WHO) 26 for classification of individual nutritional status. Normal weight was defined as BMI from 18.5 to $24.9 \mathrm{~kg} / \mathrm{m}^{2}$, overweight as BMI 25 to $29.9 \mathrm{~kg} / \mathrm{m}^{2}$, and obesity as $\mathrm{BMI} \geq 30 \mathrm{~kg} / \mathrm{m}^{2}$.

Waist circumference was measured to the closest $0.1 \mathrm{~cm}$ with a non-extensible tape measure at the height of the umbilicus. This mea- 
surement was taken with the individual standing upright, abdomen relaxed, arms beside the body, and feet together. Central (or abdominal) obesity was defined as $\geq 80$ and $90 \mathrm{~cm}$ for females and males, respectively 27 .

Systolic (SBP) and diastolic blood pressure (DBP) measurements were taken by trained physicians, using automatic digital devices with the cuff adjusted to the brachial circumference (model HEM712C, Omron Brazil), after the individual had rested 10 minutes in the sitting position. Three measurements were taken, and the final value was defined as the mean of the latter two measurements expressed in millimeters of mercury (mmHg). The diagnostic criterion for arterial hypertension was based on the seventh report of the United States Joint National Committee on Prevention, Detection, Evaluation and Treatment of High Blood Pressure (JNC-7) 28. High blood pressure or arterial hypertension was defined as $\mathrm{SBP} \geq 140 \mathrm{mmHg}$ or DBP $\geq 90 \mathrm{mmHg}$ or regular use of medication for hypertension (self-reported).

Information on the use of medicines that interfere in serum uric acid concentration (thiazides, furosemide, allopurinol, and tamoxifen) was also obtained during the physical examination, as was data on use of vitamin supplements.

Serum uric acid was quantified with the uricase method. Hyperuricemia was defined as serum uric acid $>6 \mathrm{mg} / \mathrm{dL}$ for women and $>7 \mathrm{mg} /$ dL for men 4,14 .

The Jaffé method was used to measure serum creatinine, and loss of renal function was defined as creatinine $>1.4 \mathrm{mg} / \mathrm{dL} 29$.

Venous blood (first sample, minimum 10 hours fasting) was used to measure glucose, lipid profile (total cholesterol, fractions, and triglycerides), uric acid, and creatinine. Two hours after a $75 \mathrm{~g}$ glucose load, the second sample was taken to measure plasma glucose only, using the glucose oxidase method. The glucose load was only used in individuals who did not report a previous diagnosis of diabetes mellitus, who were not on medication for diabetes, and presented capillary fasting glucose $<200 \mathrm{mg} / \mathrm{dL}$. Capillary blood glucose was measured with a glucose meter (Glucostix/ Glucometer System). Blood glucose alterations were classified according to WHO criteria 30 .

Enzymatic kits were use to quantify lipoproteins. Lipid profile alterations were diagnosed on the basis of information on use of lipid-lowering drugs and cutoff points recommended by the National Cholesterol Education Program - ATP III 31: total cholesterol $\geq 200 \mathrm{mg} / \mathrm{dL}$, LDL-cholesterol $\geq$ $130 \mathrm{mg} / \mathrm{dL}$, HDL-cholesterol $<45 \mathrm{mg} / \mathrm{dL}$, or triglycerides $\geq 150 \mathrm{mg} / \mathrm{dL}$.

Individuals were defined as on use of uric acid-increasing medication with the following drugs: thiazides, furosemide, allopurinol, and tamoxifen 2,22 .

\section{Statistical analysis}

The chi-square test was used for comparisons of individuals with or without hyperuricemia according to health-related, socio-demographic, and anthropometric variables (in categorical form). The measure of association was point prevalence ratio (PR) with a $95 \%$ confidence interval $(95 \% \mathrm{CI})$.

In order to verify the existence of associations between habitual diet and hyperuricemia, dietary variables were adjusted for total calories as recommended by Willet 32 . To describe the data, the dietary values were grouped in consumption tertiles, and for each tertile we obtained the median nutrient consumption, number of cases of hyperuricemia, and PR values.

A Poisson regression model was used to adjust the effects of the main target variables - total calories, lipids, saturated fats, alcohol, processed meats, fish, milk and dairy products (values for dietary variables in tertiles), body mass index, central obesity - on hyperuricemia for the control variables (gender, generation, age, marital status, smoking, arterial hypertension, serum creatinine $>1.4 \mathrm{mg} / \mathrm{dL}$, degree of glucose tolerance, hypercholesterolemia, hypertriglyceridemia, elevated LDL, and use of medication). These variables were selected because they showed p-values $<0.20$ in the crude analysis. These procedures were repeated separately for males and females, for the presence of arterial hypertension, and after exclusion of individuals on medication.

The data were analyzed with Stata, version 10.0 for Windows (Stata Corp., College Station, USA).

\section{Results}

Among the 1,330 Japanese-Brazilians that participated in this study, 470 (35.3\%; 95\%CI: 32.8-38.0) presented uric acid levels consistent with hyperuricemia, while only 19 individuals (4\%) had a previous diagnostic of this condition. Table 1 shows data on the Japanese-Brazilians' demographic and social characteristics according to presence of hyperuricemia. Elevated serum uric acid levels were more frequent in males ( $\mathrm{PR}=$ 1.76; 95\%CI: 1.52-2.05) and individuals 55 years or older (PR = 1.18; 95\%CI: 1.01-1.37). There was a similar distribution of Japanese-Brazilians with and without hyperuricemia according to generation and marital status ( $\mathrm{p}>0.05)$. 
Number (percentage) of Japanese-Brazilians with hyperuricemia, p-values, and prevalence ratios according to demographic and social characteristics. Bauru, São Paulo State, Brazil, 1999-2000.

\begin{tabular}{|c|c|c|c|c|c|c|c|c|}
\hline \multirow[t]{3}{*}{ Variable } & \multicolumn{6}{|c|}{ Hyperuricemia } & \multirow[t]{3}{*}{$\mathrm{p}$-value * } & \multirow[t]{3}{*}{ PR $(95 \% \mathrm{Cl})$} \\
\hline & \multicolumn{2}{|c|}{ Yes } & \multicolumn{2}{|c|}{ No } & \multicolumn{2}{|c|}{ Total } & & \\
\hline & $\mathbf{n}$ & $\%$ & $\mathbf{n}$ & $\%$ & $\mathbf{n}$ & $\%$ & & \\
\hline \multicolumn{9}{|l|}{ Gender } \\
\hline Male & 283 & 46 & 331 & 54 & 614 & 100 & $<0.001$ & $1.76(1.52-2.05)$ \\
\hline Female & 187 & 26 & 529 & 74 & 716 & 100 & & 1.00 \\
\hline \multicolumn{9}{|l|}{ Age bracket (years) } \\
\hline$\geq 55$ & 288 & 38 & 475 & 62 & 763 & 100 & 0.033 & $1.18(1.01-1.37)$ \\
\hline$<55$ & 182 & 32 & 385 & 68 & 567 & 100 & & 1.00 \\
\hline \multicolumn{9}{|l|}{ Generation } \\
\hline Second (Nisei) & 383 & 36 & 678 & 64 & 1,061 & 100 & 0.180 & $1.14(0.94-1.39)$ \\
\hline First (Issei) & 81 & 32 & 175 & 68 & 256 & 100 & & 1.00 \\
\hline \multicolumn{9}{|l|}{ Marital status } \\
\hline Married & 370 & 37 & 642 & 63 & 1,102 & 100 & 0.083 & $1.17(0.98-1.41)$ \\
\hline Other ** & 97 & 31 & 214 & 69 & 311 & 100 & & 1.00 \\
\hline
\end{tabular}

PR: prevalence ratio; $95 \% \mathrm{Cl}$ : 95\% confidence interval.

* $p$-values for chi-square test;

** Other: single, widow(er), separated, or divorced.

In both men and women, prevalence of hyperuricemia was lower among younger individuals (men $49 \%$ and women 24\%); however, this difference was only statistically significant in women (women $<55$ years, $24 \%$ and women $\geq 55$ years, $76 \% ; \mathrm{p}<0.05)$.

Table 2 shows the hyperuricemia prevalence rates according to anthropometric and health characteristics. Among Japanese-Brazilians with overweight or obesity, the hyperuricemia rates were 2.25 (95\%CI: 1.83-2.77) and 3.25 times higher (95\%CI: $2.50-4.23)$ than in normal weight individuals. In the presence of central obesity, prevalence of hyperuricemia was 2.36 times higher (95\%CI: 2.01-2.78) than in individuals without this condition. Higher hyperuricemia prevalence rates were found in individuals with co-morbidities like arterial hypertension $(\mathrm{PR}=1.54$; 95\%CI: 1.34-1.78), glucose intolerance (altered fasting glucose: PR = 1.69; 95\%CI: 1.25-2.29; decreased glucose tolerance: $\mathrm{PR}=2.08$; 95\%CI: 1.39-3.11; diabetes mellitus: $\mathrm{PR}=2.32$; 95\%CI: $1.73-3.12$ ), hypercholesterolemia $(\mathrm{PR}=1.30$; 95\%CI: 1.11 1.52), hypertriglyceridemia ( $\mathrm{PR}=2.34$; 95\%CI: 1.90-2.88), and smoking (PR $=1.30$; 95\%CI: 1.13 1.51 ), when compared to individuals without these conditions. Of the 32 individuals with loss of renal function (assessed as elevated creatinine level), 20 (62.5\%) presented hyperuricemia ( $\mathrm{PR}=1.80 ; 95 \% \mathrm{CI}: 1.36-2.28)$. No associations were observed between prevalence of hyperuri- cemia and altered HDL and LDL-cholesterol levels, or individuals with a history of cancer (data not shown).

Among individuals on hyperuricemic medication (especially diuretics, $\mathrm{n}=110$ ), 69 presented hyperuricemia (Table 2); this proportion was higher than among individuals not on such medication (PR = 1.91; 95\%CI: 1.62-2.25). Only 31 individuals $(2.3 \%)$ used vitamin $\mathrm{C}$ supplements, 10 of whom showed hyperuricemia (data not shown).

Table 3 shows higher hyperuricemia rates among individuals that consumed more alcohol per day (PR = 1.56; 95\%CI: 1.26-1.92) and fewer dairy products ( $\mathrm{PR}=0.64$; 95\%CI: 0.51-0.81).

Table 4 shows the results from the Poisson regression model. There was an association between hyperuricemia and gender, higher BMI (overweight and obesity), central obesity, hypertriglyceridemia, and hyperuricemic medication, independently of variables like diet, age, generation, marital status, smoking, arterial hypertension, glucose tolerance, hypercholesterolemia, elevated LDL, and serum creatinine $>1.4 \mathrm{mg} / \mathrm{dL}$.

In the analysis by gender, among women, age was also associated positively with hyperuricemia (PR $=1.95$; 95\%CI: 1.36-2.78), while among men, the use of medication lost its statistical significance and consumption of saturated fats was associated negatively with hyperuricemia (2nd versus $1^{\text {st }}$ tertile: $\mathrm{PR}=0.72 ; 95 \% \mathrm{CI}: 0.53-0.98$ ) 
Number (percentage) of Japanese-Brazilians with hyperuricemia, p-values, and prevalence ratios according to anthropometric and health characteristics. Bauru, São Paulo State, Brazil, 1999-2000.

\begin{tabular}{|c|c|c|c|c|c|c|c|c|}
\hline \multirow[t]{3}{*}{ Variable } & \multicolumn{6}{|c|}{ Hyperuricemia } & \multirow[t]{3}{*}{ p-value * } & \multirow[t]{3}{*}{ PR $(95 \% \mathrm{Cl})$} \\
\hline & \multicolumn{2}{|c|}{ Yes } & \multicolumn{2}{|c|}{ No } & \multicolumn{2}{|c|}{ Total } & & \\
\hline & $\mathbf{n}$ & $\%$ & $\mathbf{n}$ & $\%$ & $\mathbf{n}$ & $\%$ & & \\
\hline \multicolumn{9}{|l|}{ Body mass index $\left(\mathrm{kg} / \mathrm{m}^{2}\right)$} \\
\hline Underweight & 7 & 18 & 33 & 82 & 40 & 100 & $<0.001$ & $0.82(0.39-1.76)$ \\
\hline Normal weight & 145 & 21 & 538 & 79 & 683 & 100 & & 1.00 \\
\hline Overweight & 228 & 48 & 249 & 52 & 477 & 100 & & $2.25(1.83-2.77)$ \\
\hline Obesity & 89 & 69 & 40 & 31 & 129 & 100 & & $3.25(2.50-4.23)$ \\
\hline \multicolumn{9}{|l|}{ Central obesity } \\
\hline Yes & 306 & 50 & 301 & 50 & 607 & 100 & $<0.001$ & $2.36(2.01-2.78)$ \\
\hline No & 163 & 23 & 559 & 77 & 722 & 100 & & 1.00 \\
\hline \multicolumn{9}{|l|}{ Arterial hypertension } \\
\hline Yes & 229 & 45 & 278 & 55 & 507 & 100 & $<0.001$ & $1.54(1.34-1.78)$ \\
\hline No & 241 & 29 & 581 & 71 & 822 & 100 & & 1.00 \\
\hline \multicolumn{9}{|l|}{ Glucose tolerance } \\
\hline Normal & 56 & 20 & 228 & 80 & 284 & 100 & $<0.001$ & 1.00 \\
\hline Altered fasting glucose & 158 & 33 & 316 & 67 & 474 & 100 & & $1.69(1.25-2.29)$ \\
\hline Decreased glucose tolerance & 41 & 41 & 59 & 59 & 100 & 100 & & $2.08(1.39-3.11)$ \\
\hline Diabetes & 212 & 46 & 251 & 54 & 463 & 100 & & $2.32(1.73-3.12)$ \\
\hline \multicolumn{9}{|l|}{ Hypercholesterolemia } \\
\hline Yes & 324 & 39 & 515 & 61 & 839 & 100 & 0.001 & $1.30(1.11-1.52)$ \\
\hline No & 146 & 30 & 345 & 70 & 491 & 100 & & 1.00 \\
\hline \multicolumn{9}{|l|}{ Hypertriglyceridemia } \\
\hline Yes & 379 & 44 & 489 & 56 & 868 & 100 & $<0.001$ & $2.34(1.90-2.88)$ \\
\hline No & 83 & 19 & 361 & 81 & 444 & 100 & & 1.00 \\
\hline \multicolumn{9}{|l|}{ Smoking } \\
\hline Yes (current or former) & 173 & 42 & 237 & 58 & 906 & 100 & $<0.001$ & $1.30(1.13-1.51)$ \\
\hline No & 293 & 32 & 613 & 68 & 410 & 100 & & 1.00 \\
\hline \multicolumn{9}{|l|}{ Use of medication } \\
\hline Yes ** & 69 & 63 & 41 & 37 & 110 & 100 & $<0.001$ & $1.91(1.62-2.25)$ \\
\hline No & 401 & 33 & 819 & 67 & 1,220 & 100 & & 1.00 \\
\hline \multicolumn{9}{|l|}{ Serum creatinine $>1.4 \mathrm{mg} / \mathrm{dL}$} \\
\hline Yes & 20 & 63 & 12 & 37 & 32 & 100 & 0.001 & $1.80(1.36-2.38)$ \\
\hline No & 450 & 35 & 848 & 65 & 1,298 & 100 & & 1.00 \\
\hline
\end{tabular}

PR: prevalence ratio; $95 \% \mathrm{Cl}: 95 \%$ confidence interval.

* p-values for chi-square test;

** Medications used by participants for various treatments and that interfere in serum uric acid concentration (thiazides, furosemide, allopurinol, and tamoxifen).

Finally, upon repeating the analyses according to presence of arterial hypertension, among individuals with high blood pressure, there was a negative association between hyperuricemia and consumption of milk and dairy products (3rd versus 1 st tertile: $\mathrm{PR}=0.66$; 95\%CI: $0.47-0.94)$. The exclusion of the group of individuals on hyperuricemic medication did not alter these results.

\section{Discussion}

In this study, the high prevalence of hyperuricemia among Japanese-Brazilians (35.3\%) corroborates previous findings by the JBDSG emphasizing the high cardiovascular risk among these individuals. In this community, along with the glucose intolerance "epidemic", studies have also shown high prevalence rates for dyslipidemia, arterial hypertension, metabolic syndrome, and central obesity, all of which at higher rates than 
Number (percentage) of Japanese-Brazilians with hyperuricemia according to dietary variables (in tertiles). Bauru, São Paulo State, Brazil, $1999-2000$.

\begin{tabular}{|c|c|c|c|c|c|c|c|c|}
\hline \multirow[t]{3}{*}{ Variable } & \multicolumn{6}{|c|}{ Hyperuricemia } & \multirow[t]{3}{*}{$\mathrm{p}$-value * } & \multirow[t]{3}{*}{ PR $(95 \% \mathrm{Cl})$} \\
\hline & \multicolumn{2}{|c|}{ Yes } & \multicolumn{2}{|c|}{ No } & \multicolumn{2}{|c|}{ Total } & & \\
\hline & $\mathbf{n}$ & $\%$ & $\mathbf{n}$ & $\%$ & $\mathbf{n}$ & $\%$ & & \\
\hline \multicolumn{9}{|l|}{ Calories (kcal) } \\
\hline First tertile $(1,433)$ & 131 & 31 & 296 & 69 & 427 & 100 & 0.060 & 1.00 \\
\hline Second tertile $(1,918.8)$ & 161 & 38 & 267 & 62 & 428 & 100 & & $1.23(0.97-1.54)$ \\
\hline Third tertile $(2,506.3)$ & 159 & 37 & 269 & 63 & 428 & 100 & & $1.21(0.96-1.53)$ \\
\hline \multicolumn{9}{|l|}{ Carbohydrates (g) } \\
\hline First tertile (185.1) & 155 & 36 & 272 & 64 & 427 & 100 & 0.277 & 1.00 \\
\hline Second tertile (253.4) & 138 & 32 & 291 & 68 & 429 & 100 & & $0.89(0.70-1.11)$ \\
\hline Third tertile (341.7) & 158 & 37 & 269 & 63 & 427 & 100 & & $1.02(0.82-1.27)$ \\
\hline \multicolumn{9}{|l|}{ Proteins (g) } \\
\hline First tertile (46.1) & 156 & 38 & 256 & 62 & 412 & 100 & 0.349 & 1.00 \\
\hline Second tertile (65.2) & 148 & 35 & 281 & 65 & 429 & 100 & & $0.91(0.73-1.14)$ \\
\hline Third tertile (88.1) & 147 & 33 & 295 & 67 & 442 & 100 & & $0.88(0.70-1.10)$ \\
\hline \multicolumn{9}{|l|}{ Lipids (g) } \\
\hline First tertile (47.8) & 169 & 39 & 267 & 61 & 436 & 100 & 0.146 & 1.00 \\
\hline Second tertile (68.2) & 142 & 34 & 279 & 66 & 421 & 100 & & 0.87 (0.70-1.09) \\
\hline Third tertile (95.7) & 140 & 33 & 286 & 67 & 426 & 100 & & $0.85(0.68-1.06)$ \\
\hline \multicolumn{9}{|l|}{ Saturated fats (g) } \\
\hline First tertile (10.4) & 171 & 41 & 251 & 59 & 422 & 100 & 0.019 & 1.00 \\
\hline Second tertile (15.7) & 139 & 33 & 288 & 67 & 427 & 100 & & $0.80(0.64-1.00)$ \\
\hline Third tertile (23.9) & 141 & 33 & 293 & 67 & 434 & 100 & & $0.80(0.64-1.00)$ \\
\hline \multicolumn{9}{|l|}{ Alcohol (g/day)** } \\
\hline None & 249 & 33 & 517 & 67 & 766 & 100 & $<0.001$ & 1.00 \\
\hline $1.0-3.7$ & 71 & 28 & 187 & 72 & 258 & 100 & & $0.85(0.65-1.10)$ \\
\hline$>3.7$ & 131 & 51 & 128 & 49 & 259 & 100 & & $1.56(1.26-1.92)$ \\
\hline \multicolumn{9}{|l|}{ Red meat group (g) } \\
\hline First tertile (17.3) & 142 & 33 & 285 & 67 & 427 & 100 & 0.379 & 1.00 \\
\hline Second tertile (41.6) & 146 & 34 & 281 & 66 & 427 & 100 & & $1.03(0.82-1.30)$ \\
\hline Third tertile (80.0) & 159 & 38 & 264 & 62 & 423 & 100 & & $1.13(0.90-1.42)$ \\
\hline \multicolumn{9}{|l|}{ Processed meats group (g) } \\
\hline First tertile (2.3) & 131 & 32 & 278 & 68 & 409 & 100 & 0.127 & 1.00 \\
\hline Second tertile (8.8) & 139 & 35 & 263 & 65 & 402 & 100 & & $1.08(0.85-1.37)$ \\
\hline Third tertile (22.5) & 157 & 39 & 248 & 61 & 405 & 100 & & $1.21(0.96-1.53)$ \\
\hline \multicolumn{9}{|l|}{ Fish group (g) } \\
\hline First tertile (5.2) & 134 & 32 & 290 & 68 & 424 & 100 & 0.161 & 1.00 \\
\hline Second tertile (13.4) & 153 & 37 & 262 & 63 & 415 & 100 & & $1.17(0.93-1.47)$ \\
\hline Third tertile (32.4) & 157 & 37 & 265 & 63 & 422 & 100 & & $1.18(0.93-1.48)$ \\
\hline \multicolumn{9}{|l|}{ Milk and dairy products } \\
\hline \multicolumn{9}{|l|}{ group (g) } \\
\hline First tertile (2.1) & 181 & 42 & 247 & 58 & 428 & 100 & $<0.001$ & 1.00 \\
\hline Second tertile (56.6) & 153 & 36 & 272 & 64 & 425 & 100 & & $0.85(0.69-1.06)$ \\
\hline Third tertile (200.0) & 116 & 27 & 313 & 73 & 429 & 100 & & $0.64(0.51-0.81)$ \\
\hline \multicolumn{9}{|l|}{ Fruits group (g) } \\
\hline First tertile (132.6) & 144 & 34 & 283 & 66 & 427 & 100 & 0.666 & 1.00 \\
\hline Second tertile (331.5) & 149 & 35 & 276 & 65 & 425 & 100 & & $1.04(0.83-1.31)$ \\
\hline Third tertile (602.1) & 158 & 37 & 273 & 63 & 431 & 100 & & $1.09(0.87-1.36)$ \\
\hline
\end{tabular}

PR: prevalence ratio; $95 \% \mathrm{Cl}$ : $95 \%$ de confidence interval.

* $\mathrm{p}$-values for chi-square test;

** Due to the number of individuals that reported not consuming alcohol, we chose to set the cutoff for categories 2 and 3 as the median value of those that reported some consumption of alcoholic beverages. 
Adjusted prevalence ratios (95\% confidence interval) for presence of hyperuricemia and the remaining variables. Bauru, São Paulo State, Brazil, 1999-2000.

\begin{tabular}{lcc}
\hline Variable & \multicolumn{1}{c}{$\begin{array}{c}\text { Hyperuricemia (yes versus no) } \\
\text { Initial model } \\
\text { PR }(95 \% \mathrm{Cl})\end{array}$} & $\begin{array}{c}\text { Final model } \\
\text { PR (95\%Cl) }\end{array}$ \\
\hline $\begin{array}{l}\text { Gender (male versus female) } \\
\text { Body mass index }\left(\mathrm{kg} / \mathrm{m}^{2}\right)\end{array}$ & $1.65(1.25-2.18)$ & $1.73(1.42-2.10)$ \\
$\quad$ Underweight & $0.92(0.37-2.29)$ & $1.08(0.50-2.32)$ \\
$\quad$ Normal weight & 1.00 & 1.00 \\
$\quad \begin{array}{l}\text { Overweight } \\
\text { Obesity }\end{array}$ & $1.56(1.16-2.11)$ & $1.55(1.19-2.02)$ \\
Central obesity (yes versus no) & $1.96(1.33-2.89)$ & $1.95(1.38-2.75)$ \\
Hypertriglyceridemia (yes versus no) & $1.33(1.01-1.80)$ & $1.42(1.09-1.84)$ \\
Use of medications (yes versus no) & $1.52(1.16-2.00)$ & $1.68(1.31-2.15)$ \\
\hline
\end{tabular}

PR: prevalence ratio; $95 \% \mathrm{Cl}$ : 95\% confidence interval.

Note: variables included in the initial model: total calories, lipids, saturated fats, alcohol, processed meats group, fish group, milk and dairy products group, citric fruits group, age, generation, marital status, smoking, arterial hypertension, glucose tolerance, hypercholesterolemia, elevated LDL, and serum creatinine $>1.4 \mathrm{mg} / \mathrm{dL}$.

in the overall Brazilian population or in Japanese living in Japan 19,21,33,34.

In Brazil, there are no available data from population-based epidemiological studies on the occurrence of altered serum uric acid levels. Despite the recognition of the limitations in the direct comparison between findings from the current study and those of other researchers (particularly because of the different age structures in these population groups and the different approaches used), one can state that the prevalence of hyperuricemia detected among Japanese-Brazilians (35.3\%) was higher than described in international studies $11,35,36$. As identified in previous publications by the JBDSG 19,21,33,34, this community also displays high rates of co-morbidities associated with hyperuricemia, thus characterizing high risk for cardiovascular diseases.

The literature has still not totally elucidated the mechanism by which excess body fat leads to increased serum uric acid. In addition to the increase in endogenous production of urate, evidence shows that accumulated visceral fat leads to an increase in free fatty acids and tumor necrosis factor alpha (TNF- $\alpha$ ), together with a decrease in adiponectin concentration, which leads in turn to reduced renal excretion of uric acid 4,8,14. The current study's findings show a positive association between elevated serum uric acid and excess body weight and central obesity. Such findings are consistent with those of other studies $37,38,39$.

Hypertriglyceridemia is found frequently in individuals with asymptomatic hyperuricemia or gout 5,14 . Some studies suggest that hyper- triglyceridemia and arteriosclerosis result from metabolic abnormalities inherent to gout 3,40 . According to the current study's data, hyperuricemia and hypertriglyceridemia are positively associated with each other. This relationship is still not totally clear in the literature, but there is purportedly a reduced renal excretion of uric acid in individuals with hyperuricemia and dyslipidemia 41 . Other studies have also shown a positive association between hypertriglyceridemia and hyperuricemia 37,38,39,41.

Uric acid renal transport is explained by a four-component system: glomerular filtration, proximal tubular reabsorption, tubular secretion, and post-secretory reabsorption. This system allows understanding the action of drugs that decrease urinary uric acid excretion (which increase serum uric acid levels) and those that augment urinary uric acid excretion (and decrease serum uric acid levels) 4,14 . Some drugs used for the treatment of arterial hypertension and other diseases like neoplasms increase the serum uric level levels. This effect is due to the fact that they decrease urinary uric acid excretion, which leads to renal tubular reabsorption of uric acid, resulting in most cases from stimulation of the URAT-1 transporter which promotes a reduction in the urinary excretion of this substance 2,5,18. Among the Japanese-Brazilians who were using hyperuricemic medication, there was a higher prevalence of excess uric acid. Other authors have reported a similar association 12,39.

This study showed differences between the genders and age brackets. The most important 
difference was in women over 55 years of age, probably due to menopause, common in women in this age bracket, which leads to increased serum uric acid due to the deficiency of estrogen, a hormone that purportedly increases urinary excretion of uric acid 3,39.

Among men the results were different: the use of hyperuricemic drugs lost its statistical significance, and consumption of saturated fats was negatively associated with the prevalence of hyperuricemia, that is, there was a lower prevalence of hyperuricemia among men that consumed less saturated fat. This finding lacks backing in the scientific literature and probably reflects a phenomenon frequently cited in cross-sectional studies - reverse causality - given that one observes high rates of metabolic alterations like arterial hypertension and diabetes mellitus among Japanese-Brazilians, suggesting that they have modified their eating habits.

When analyzing this sample of Japanese-Brazilians according to presence of arterial hypertension, among the individuals with high blood pressure there was a negative association between consumption of milk and dairy products and increased plasma uric acid levels, indicating that hyperuricemia rates were lower among individuals that consumed more milk and dairy products. According to a review study by Schlesinger ${ }^{9}$, casein and lactalbumin - proteins present in milk - apparently play a uric acid-excreting role, since they are related to reductions in serum uric acid in healthy individuals; in addition, adherence to a dairy-poor diet can lead to an increase in uric acid levels. The current study's findings were also consistent with results reported elsewhere in the literature 4,11,13.

Alcohol abuse can contribute to the occurrence of hyperuricemia due to the increase in metabolic production of uric acid and the decrease in renal uric acid excretion 2,4. A cohort study in Taiwan from 1993 to 1996 showed association between alcohol consumption and hyperuricemia in males, while $11.7 \mathrm{~g}$ of ethanol per day from beer increased serum uric acid by $0.08 \mathrm{mg} /$ $\mathrm{dL}$ 11. However, in the current study, the association between alcohol intake and hyperuricemia lost is statistical significance after adjusting for control variables. In the results shown here, this association was not maintained after multivariate adjustment. Still, it is important to highlight that in the studies evaluating alcohol content according to type of beverage, the positive association between alcohol consumption and hyperuricemia was mostly related to beer 4,11,16.

The relationship between consumption of animal protein (especially red meat) and hyperuricemia has been reported in the literature ${ }^{4,8,9}$.
However, in the current study such an association did not show statistical significance in the crude analysis.

This study presents some limitations: (1) the cross-sectional design does not allow inferring a causal relationship between the independent variables and the outcome; (2) despite the recommendation by various studies concerning the ideal anatomical point (midway between the anterior superior iliac spine and the last rib) for measuring the waist circumference, the researchers in the second phase of the JBDSG study opted to use the most convenient anatomical landmark, the umbilical scar; (3) one cannot rule out the possibility of data collection errors on habitual food consumption, since the latter depends exclusively on the interviewees' recall capacity (although the use of trained interviewers and a previously tested instrument possibly minimized this bias). In addition, despite the known inherent limitations of the FFQ (Food Frequency Questionnaire), it shows good capacity to identify subjects in extreme consumption categories; (4) dietary information was collected by means of a FFQ validated for the study population, however more precise data on the types of food consumed and their purine content could not be assessed due to methodological and logistic difficulties; (5) no information was available on acute weight loss and isolated fructose consumption; and (6) despite the lack of information on food consumption for $3.5 \%$ of the subjects ( $n=47$ ), there is no reason to suppose that the findings would have been different if these data had been available for all of the subjects (this group was considered small and incapable of modifying the findings).

Finally, according to this study, gender (male), excess weight (overweight or obesity), hypertriglyceridemia, and use of medication that interferes in serum uric acid concentration were associated with hyperuricemia, independently of other risk factors. During the multivariate analysis the associations that had been observed between hyperuricemia and dietary variables (alcohol and milk and dairy product consumption) lost their statistical significance.

The findings suggest the need (in both clinical practice and public health) to monitor the effect of medications that can affect uric acid metabolism, to encourage consumption of three portions of milk and dairy products, and to promote changes in individuals' nutritional profile, like reduction in weight, body fat, and serum triglycerides, thus contributing to a decrease in hyperuricemia rates. 


\section{Resumo}

O objetivo deste estudo transversal foi estimar a prevalência de hiperuricemia e fatores associados entre nipo-brasileiros. Obtiveram-se informações sobre variáveis demográficas, de saúde, dietéticas e bioquímicas. O teste qui-quadrado e razões de prevalências foram utilizados como medidas de associação. 35,3\% dos sujeitos tinham hiperuricemia e esta acometeu, principalmente, tabagistas, homens, com faixa etária $\geq 55$ anos, com outras comorbidades, em uso de drogas hiperuricemiantes, com creatinina sérica elevada, com maior ingestão de álcool e menor de laticínios. Em análise múltipla permaneceram significantes as associações com o sexo, excesso de peso, obesidade central, hipertrigliceridemia e uso de medicamentos. Entre os homens, o menor consumo de gorduras saturadas associou-se à hiperuricemia. Entre hipertensos ocorreu associação negativa com o consumo de laticínios. A alta prevalência de hiperuricemia indica que mudanças no perfil nutricional e controle das comorbidades associadas podem contribuir para minimizar a ocorrência dessa anormalidade.

Hiperuricemia; Dieta; Nipo-Brasileiros

\section{Contributors}

J. Poletto was responsible for the data analysis, interpretation, elaboration, and final version of the article. H. A. Harima participated in the data analysis, interpretation, elaboration, and final version of the article. S. R. G. Ferreira was responsible for the elaboration and implementation of the second phase of the JBDSG study and revised the manuscript. S. G. A. Gimeno participated in the elaboration and implementation of the second phase of the JBDSG study, data analysis, interpretation, elaboration, and final version of the article.

\section{Acknowledgments}

The authors wish to thank the Japanese-Brazilian community of Bauru, São Paulo State, for their participation, without which this study would not have been possible, and all the researchers from the Japanese-Brazilian Diabetes Study Group, the São Paulo State Research Foundation (FAPESP) for funding the second phase of the study, and the Graduate Studies Coordinating Board (CAPES) for providing a research grant.

\section{References}

1. Portero-McLellan KC, Bernardi JLD, Barbalho SM Abordagem metabólica e dietética na hiperuricemia e na gota. Rev Bras Nutr Clin 2009; 24:29-32.

2. Luk AJ, Simkim PA. Epidemiology of hyperuricemia and gout. Am J Manag Care 2005; 11:S435-42.

3. Feig DI, Kang D-H, Johnson RJ. Uric acid and cardiovascular risk. N Engl J Med 2008; 359:1811-21.

4. Choi HK, Mount DB, Reginato AM. Pathogenesis of gout. Ann Intern Med 2005; 143:499-516.

5. Alexander S. Developments in the scientific and clinical understanding of gout. Arthritis Res Ther 2008; 10:221-6.

6. Alderman MH. Podagra, uric acid and cardiovascular disease. Circulation 2007; 116:880-3.

7. Lyu L-C, Hsu C-Y, Yeh C-Y, Lee M-S, Huang S-H, Chen C-L. A case-control study of the association of diet and obesity with gout in Taiwan. Am J Clin Nutr 2003; 78:690-701
8. Peixoto MRSG, Monego ET, Jardim PCBV, Carvalho MM, Sousa ALL, Oliveira JS, et al. Dieta e medicamentos no tratamento da hiperuricemia em pacientes hipertensos. Arq Bras Cardiol 2001; 76:463-7.

9. Schlesinger N. Dietary factors and hyperuricemia. Curr Pharm Des 2005; 11:4133-8.

10. Pires ISC, Rosado GP, Azeredo RMC, Neves MB, Miranda LS. Composição centesimal, perdas de peso e maciez de lombo (longissimus dorsi) suíno submetido a diferentes tratamentos de congelamento e descongelamento. Rev Nutr 2002; 15:163-72.

11. Yu K-H, See L-C, Huang Y-C, Yang C-H, Sun J-H. Dietary factors associated with hyperuricemia in adults. Semin Arthritis Rheum 2008; 37:243-50.

12. Yano K, Rhoads GG, Kagan A. Epidemiology of serum uric acid among 8000 Japanese-American men in Hawaii. J Chron Dis 1977; 30:171-84. 
13. Choi HK, Atkinson K, Karlson EW, Willett W, Curhan G. Purine-rich foods, dairy and protein intake, and the risk of gout in men. N Engl J Med 2004; 350:1093-110.

14. Nuki G. Disorders of purin metabolism. In: Weatherall DJ, Ledingham JGG, Warrel DA, editors. Oxford Textbook of Medicine. v. 1. 2nd Ed. New York: Oxford University Press; 1996. p. 9123-35.

15. Gagliardi ACM, Miname MH, Santos RD. Uric acid: a marker of increased cardiovascular risk. Atherosclerosis 2009; 202:11-7.

16. Yamamoto T, Moriwaki Y, Takahashi S. Effect of ethanol on metabolism of purine bases (hypoxanthine, xanthine, and uric acid). Clin Chim Acta 2005; 356:35-57.

17. Cunha RS, Ferreira AVL, Silva IO, Cunha Filho RS, Molina MDCB, Herkenhoff FLV, et al. Determinantes populacionais da rigidez aórtica. Rev Bras Hipertens 2004; 11:169-74.

18. Karlson P, Gerok W, Gross W. Patobioquímica. Rio de Janeiro: Editora Guanabara Koogan; 1982.

19. Lerário DDG, Gimeno SG, Franco LJ, Iunes M, Ferreira SRG; Grupo de Estudo de Diabetes na Comunidade Nipo-Brasileira. Excesso de peso e gordura abdominal para a síndrome metabólica em nipobrasileiros. Rev Saúde Pública 2002; 36:4-11.

20. Gimeno SAG, Ferreira SRG, Franco LJ, Hirai A, Matsumura L, Moisés RCS. Prevalence and 7-year incidence of type II diabetes mellitus in a Japanese Brazilian population: an alarming public health problem. Diabetologia 2002; 45:1635-8.

21. Freire R, Cardoso M, Shinzato A, Ferreira S. Nutritional status of Japanese-Brazilian subjects: comparison across gender and generation. Br J Nutr 2003; 89:705-12.

22. Cardoso MA, Kida AA, Tomita LY, Stocco PR. Reproducibility and validity of a food frequency questionnaire among women of Japanese ancestry living in Brazil. Nutr Res 2001; 21:725-33.

23. Block G, Coyle LM, Hartman AM, Scoppa SM. Revision of dietary analysis software for the health habits and history questionnaire. Am J Epidemiol 1994; 139:1190-6.

24. Instituto Brasileiro de Geografia e Estatística. Tabela de composição de alimentos. 4a Ed. Rio de Janeiro: Instituto Brasileiro de Geografia e Estatística; 1996.

25. Resources Research Council, Science and Technology Agency. Standard tables of food composition in Japan. $4^{\text {th }}$ Ed. Tokyo: Women's University of Nutrition Press; 1993.

26. World Health Organization. Obesity: preventing and managing the global epidemic. Report of WHO Consultation on Obesity. Geneva: World Health Organization; 1998.

27. Inoue S, Zimmet P. The Asian-Pacific perspective: redefining obesity and its treatment. Sidney: Health Communications Australia Pty; 2000.
28. Chobanian AV, Bakris GL, Black HR, Cushman WC, Green LA, Izzo JL, et al. The seventh report of the Joint National Committee on Prevention, Detection, Evaluation and Treatment of High Blood Pressure (JNC-7). Hypertension 2003; 42:1206-52.

29. Kirsztajn GM. Avaliação do ritmo da filtração glomerular. J Bras Patol Med Lab 2007; 43:257-64.

30. Alberti KGMM, Zimmet PZ. Definition, diagnosis and classification of diabetes mellitus and its complications. Geneva: World Health Organization; 1999.

31. National Cholesterol Education Program. Executive Summary of the Third Report of the National Cholesterol Education Program (NCEP). Expert panel on detection, evaluation and treatment of high blood cholesterol in adults. JAMA 2001; 285:2486-97.

32. Willet W. Nutritional epidemiology. Monographs in epidemiology and biostatistics. v. 30. 2nd Ed. New York: Oxford University Press; 1998.

33. Gimeno SGA, Hirai AT, Harima HA, Kikuchi MY, Simony RF, Barros Jr. N, et al. Fat and fiber consumption are associated with peripheral arterial disease in a cross-sectional study of Japanese-Brazilian population. Circ J 2008; 72:44-50.

34. Japanese-Brazilian Diabetes Study Group. Diabetes mellitus e doenças associadas em nipo-brasileiros. São Paulo: Departamento de Medicina Preventiva, Universidade Federal de São Paulo; 2004.

35. Sadr SM, Namayandeh SM, Moadares MM, Rafiei M. Serum uric acid levels and its association with cardiovascular risk factors. Iran J Public Health 2009; 38:53-9.

36. Sari I, Akar S, Pakoz B, Sisman AR, Gurler O, Birlik $\mathrm{M}$, et al. Hyperuricemia and its related factors in an urban population, Izmir, Turkey. Rheumatol Int 2009; 29:869-74.

37. Tamba S, Nishizawa H, Funahashi T, Okauchi Y, Ogawa T, Noguchi M, et al. Relationship between the serum uric acid level, visceral fat accumulation and serum adiponectin concentration in Japanese men. Inter Med 2008; 47:1175-80.

38. Endorgan D, Gullu H, Caliskan M, Yildirim E, Bilgi M, Ulus T, et al. Relationship of serum uric acid to measures of endothelial function and atherosclerosis in healthy adults. Int J Clin Pract 2005; 59:1276-82.

39. Conen D, Wietlisbach V, Bovet P, Shamlaye C, Riesen W, Paccaud F, et al. Prevalence of hyperuricemia and relation of serum uric acid with cardiovascular risk factors in a developing country. BMC Public Health 2004; 4:1-9.

40. Feldman EB, Wallace SL. Hypertriglyceridemia in gout. Circulation 1964; 29:508-13.

41. Cardona F, Tinahones JF, Collantes E, Escudero A, García-Fuentes E, Soriguer FJ. Contribution of polymorphisms in the apolipoprotein AI-CIII-AIV cluster to hyperlipidaemia in patients with gout. Ann Rheum Dis 2005; 64:85-8.

Submitted on 26/May/2009

Final version resubmitted on $01 /$ Jun/2010

Approved on 07/Jun/2010 